\title{
Migration of Neuroblasts Along Preexisting Axonal Tracts During Prenatal Cerebellar Development
}

\author{
Richard O. Hynes, “ Ramila Patel, ${ }^{\star}+$ and Robert H. Miller ${ }^{\dagger}, 1$ \\ ${ }^{*}$ Center for Cancer Research and Department of Biology, Massachusetts Institute of Technology, Cambridge, \\ Massachusetts 02139, and +Medical Research Council Neuroimmunology Project, Department of Zoology, \\ University College, London WC2E 6BT, England
}

During prenatal development of the cerebellum in rats, a secondary stem cell layer, the external granular, or germinal, layer (EGL) develops at the pial surface of the cerebellar anlage. The EGL cells arise in a region at the caudolateral margin of the fourth ventricle, and the cells migrate over the surface of the developing cerebellum. A key question is how this migration is guided. We have investigated the possible role of the extracellular matrix protein, fibronectin, and find none present in the EGL during the migration. Instead, we find that the EGL neuroblasts migrate in close contact with axons that are present prior to the onset of migration. It appears that these axons serve as the substrate for EGL neuroblast migration and that axonal guidance of cell migration may be a third general mechanism to be added to the previously studied guidance by glial processes and extracellular matrix.

In many situations during development, cells originate in one location and migrate, sometimes over long distances, to their final sites of differentiation. The means whereby cells find their way to their correct destinations are not well understood. In principle, several mechanisms are possible, falling under the general headings of (1) random migration combined with selective retention, (2) chemotaxis, and (3) guidance by a preexisting pathway of some kind.

During development of the vertebrate nervous system, there is extensive cell migration, and the existing evidence tends to support the third of these models: substrate guidance. Two general mechanisms of this type have been suggested. During development of the PNS, neural crest cells migrate over large distances and appear to follow pathways in extracellular spaces containing extracellular matrices (Lofberg et al., 1980; Newgreen et al., 1982; Tosney, 1978, 1982). The evidence strongly suggests that the neural crest cells are guided by preexisting pathways composed of extracellular matrix.

In contrast, in the CNS, there is rather little intercellular space

\footnotetext{
Received Jan. 2, 1985; revised June 24, 1985; accepted June 25, 1985.

This work was initiated in Martin Raff's laboratory at University College, London, and was made possible by the friendly and stimulating atmosphere of the MRC Neuroimmunology group. We are indebted to Martin Raff and all his colleagues for their advice, encouragement, and help in initiating us into the mysteries of neuroanatomy. We would also like to thank Miyuki Yamamoto and Mike Edwards of the Shriver Center for many helpful discussions, and Martin Raff Jack Price, and Steve Burden for their criticisms of the manuscript. This work was supported by the MRC Neuroimmunology project grant, the USPHS, National Cancer Institute (Grant R01 CA17007), and a fellowship award to R.O.H. from the John Simon Guggenheim Memorial Foundation.

Correspondence should be addressed to Dr. Hynes, Center for Cancer Research, 40 Ames Street, Bldg. E17, Rm. 227, Massachusetts Institute of Technology, Cambridge, MA 02139.

' Present address: Department of Developmental Genetics and Anatomy, Case Western Reserve University, Cleveland, OH 44106

Copyright (C) 1986 Society for Neuroscience $0270-6474 / 86 / 030867-10 \$ 02.00 / 0$
}

or matrix, and evidence has been presented supporting the idea that neuroblast migration, which is frequently in a radial direction in the developing neural tube and its derivatives, is guided by the processes of radial glial cells (Rakic, 1971, 1972, 1981; Sidman and Rakic, 1973). The neuroblasts appear to migrate in close contact with the radial glial processes, and it is thought that the latter act as specific substrata promoting and/or guiding the migration of these cells.

The development of the cerebellum is an example of a situation in which cell migration clearly plays a crucial role in the final architecture and, presumably, therefore in the physiology of the system. There are several waves of migration. Prenatally, Purkinje cells, Golgi cells, and deep nuclear neurons originate in the ventricular zone and migrate into the body of the cerebellar anlage. This is a radial migration and quite likely takes place on radial glial cells, although there is no direct evidence for this mechanism in this case. The deep nuclear neurons subsequently migrate away from the Purkinje cells to their final locations. Meanwhile, a second migration begins. A new stem cell layer, known as the external granule (or germinal) layer (EGL) originates in the ventricular region at the caudal margin of the fourth ventricle. From here, the cells migrate over the outer (dorsal) surface of the devcloping cerebellum and, by the time of birth, have come to cover this surface completely (Altman, 1982; Altman and Bayer, 1978a; Korneliussen, 1968; Miale and Sidman, 1961). Postnatally this EGL gives rise to several types of neurons, but predominantly to the granule cells, which make up $90 \%$ of the neurons of the cerebellum. Thesc granule cells arise from the mitotic external granular cells and migrate inward from the pial surface past the layer of Purkinje cells and into the future internal granular layer (Altman, 1972a, b, 1982; Rakic, 1971, 1973). This postnatal migration of postmitotic but undifferentiated granule cells has been shown to follow the processes of Bergmann glia, a particular type of radial glia found in the cerebellum (Rakic, 1971, 1973).

While the individual migrations of Purkinje cells prenatally and of granule cells postnatally are thought to occur on glial cell processes, there has been little investigation of the prenatal $\mathrm{mi}$ gration en masse of the EGL. We were therefore intrigued by the report that the prenatal EGL contains fibronectin (Hatten et al., 1982). Fibronectin is an extracellular matrix glycoprotein that promotes migration of several cell types and that has been implicated in several embryonic cell migrations (Boucaut et al., 1984; Hynes, 1981; Hynes and Yamada, 1982; Lee et al., 1984). One of the best studied systems of cell migration, in which fibronectin appears to play an important role, is the neural crest (Duband and Thiery, 1982; Mayer et al., 1981; Newgreen and Thiery, 1980; Rovasio et al., 1983; Thiery et al., 1982). However, previous work had suggested that there is little, if any, fibronectin within the body of the CNS, although fibronectin is found in the extracellular matrices of the meninges and the 
choroid plexus, and around blood vessels (Jones et al., 1982; Minier et al., 1981; Paetau et al., 1980; Schachner et al., 1978). It would be of some interest if fibronectin were to appear at the time of tangential cell migration of the EGL early in cerebellar development. This mass migration of cells is superficially more like neural crest migration than like the migration of individual cells along Bergmann glia.

Therefore, we decided to investigate this migration further, and we report here the results of this work. We were unable to confirm a role for fibronectin-rich extracellular matrix in this system, but our investigation has led to the observation that the migration of the EGL appears to occur on preexisting arrays of axonal processes. We suggest that axonal guidance of neuroblast migration may represent another form of guidance that could play an important part in development.

\section{Materials and Methods}

\section{Animals}

Studies were performed on rat fetuses from female Sprague-Dawley (Imperial Cancer Research Fund, London) or Fisher (Charles River Laboratories, Inc., Wilmington, MA) rats. Pregnancies were timed from the day that a vaginal plug was detected. This was taken as embryonic day one (E1), according to Altman's dating scheme (Altman and Bayer, $1978 \mathrm{a}$, b). Birth occurred typically on E22 or E23. No significant differences were noted between the two strains of rats.

\section{Antisera}

Rabbit antiscra to fibronectin were raised as described by Mautner and Hynes (1977). Fibronectin was purified from the culture medium of cells or from plasma by gelatin-Sepharose affinity chromatography, and further purified for immunization by preparative SDS-PAGE. Most of the studies were done with an antiserum raised against hamster cellular fibronectin. This antiserum has been used extensively and been shown to be monospecific (Choi and Hynes, 1979; Hynes and Destree, 1978; Mautner and Hynes, 1977; Senger and Hynes, 1978). We also tested four other rabbit antisera against hamster and rat fibronectins and two monoclonal antibodies (NS7 and sp322) raised against hamster cellular fibronectin, as described by Atherton and Hynes (1981). All the antibodies gave similar results, although the titers of these two monoclonals against rat fibronectin were not high. Control sera included preimmune serum and antiserum absorbed with fibronectin-Sepharose and shown to be frce of anti-fibronectin by immunofluorescence (Hynes and Destree, 1978). These control sera were consistently negative.

\section{Immunohistochemistry}

Rat brains were dissected from fetuses of the desired age and fixed in $4 \%$ paraformaldehyde in $0.1 \mathrm{~m}$ phosphate buffer, $\mathrm{pH} 7.0$. Fixed brains were equilibrated with $30 \%$ sucrose in the same buffer and frozen in O.C.T. embedding compound (Tissue Tek, Inc.), either on dry ice or in isopentane cooled with liquid nitrogen. In some experiments, brains were frozen directly in O.C.T. without fixation. Frozen sections (usually 10 or $20 \mu \mathrm{m}$ ) were cut on a Bright cryomicrotome and placed on microscope slides coated with gelatin-alum. Sections were air-dried, incubated in $2 \%$ lysine in PBS, washed in PBS, preincubated in $10 \%$ heatinactivated fibronectin-free goat serum in PBS (antibody buffer), and incubated overnight at room temperature in rabbit anti-fibronectin serum diluted 1:100 in antibody buffer. In some experiments, the antibody buffer contained $0.1 \%$ Triton-X-100 without any noticeable effect on the results. After primary antibody staining, slides were washed three times in PBS. Unfixed sections were fixed at this point. Slides were then incubated in antibody buffer and processed either for immunofluorescence [2-3 hr incubation in fluorescein or rhodamine-conjugated antirabbit IgG (Cappel Laboratories) diluted 1:50 or 1:100 in antibody buffer, followed by three rinses in PBS] or for immunoperoxidase. The procedure for the latter method was as follows: $2 \mathrm{hr}$ in sheep anti-rabbit IgG diluted 1:50 in antibody buffer, rinsed three times in PBS, preincubated in antibody buffer, $2 \mathrm{hr}$ in peroxidase-rabbit antiperoxidase (Dako) diluted 1:50 in antibody buffer, rinsed three times in PBS and

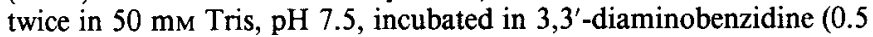
$\mathrm{mg} / \mathrm{ml})$ plus $\mathrm{H}_{2} \mathrm{O}_{2}(0.01 \%)$ or in 4-chloro-1-naphthol $(0.06 \%$ in $20 \%$ methanol, $40 \mathrm{mM}$ Tris, $\mathrm{pH} 7.5$ ) plus $\mathrm{H}_{2} \mathrm{O}_{2}(0.01 \%)$ until suitable color developed, with a final rinse in $50 \mathrm{~mm}$ Tris. Slides were then mounted in glycerol and viewed and photographed on a Zeiss microscope (Universal, Photo III or IM35).

\section{Plastic sections}

Heads from fetuses of appropriate age were fixed in $4 \%$ glutaraldehyde in $0.1 \mathrm{M}$ phosphate buffer, $\mathrm{pH} 7.4$, for $1-2 \mathrm{hr}$ at room temperature. Brains were dissected and fixed for another $3-4 \mathrm{hr}$ at $4^{\circ} \mathrm{C}$, washed in the same buffer, and postfixed in buffered $2 \% \mathrm{OsO}_{4}$ for $2 \mathrm{hr}$ at room temperature, and in $0.5 \%$ aqueous uranyl acetate solution for $30 \mathrm{~min}$. Tissues were dehydrated using ethanol and acetone and embedded in Epon 812 (Polysciences).

Plastic sections, $0.5-4 \mu \mathrm{m}$ thick, were cut on an ultramicrotome (LKBII) with a glass knife and stained with toluidine blue $(1 \%$ toluidine blue in $1 \%$ sodium borate), and then examined in the LM. Ultrathin sections for the EM were cut using a diamond knife (DuPont). Silver-gold sections were collected on 200-mesh copper grids and stained with uranyl acetate and lead citrate. Sections were examined and photographed on a Phillips 201 or a Jeol $100 \times$ EM.

\section{Results}

\section{Immunolocalization of fibronectin}

Frozen sections of prenatal cerebellum were stained with polyclonal rabbit antisera to fibronectin and the primary antibody detected either by the peroxidase-antiperoxidase (PAP) method or by fluorescent second antibody (see Materials and Methods). Figure 1 shows representative results. We concentrated particularly on embryonic days E17 and E18 during the early phases of EGL migration (Fig. 1, $A$ and $C$ ), but also investigated earlier (E16, not shown) and later (Fig. $1 B$ ) stages. In all cases, strong staining for fibronectin was observed in three locations. These were the meningeal layer around the cerebellum, the choroid plexus, and capillaries coursing through the body of the cerebellum. We did not detect any fibronectin within the neuronal regions. In particular, the migrating EGL was free of fibronectin. This was clear in the case of the PAP-stained samples, where the background staining was particularly low (Fig. $1 A$ ), and was accentuated in sections stained by indirect immunofluorescence, since the background fluorescence (which was nonspecific, as shown by controls with preimmune and absorbed sera) was lower in the EGL than elsewhere (Fig. 1, $B$ and $C$ ). Despite numerous experiments with several different rabbit antisera and two monoclonal antibodies against fibronectin, as well as with both fixed and unfixed specimens, we were unable to confirm the report of Hatten et al. (1982) of fibronectin within the EGL.

These results suggest that migration of the neuroblasts making up the EGL does not occur within a fibronectin-rich extracellular matrix, as in the case of neural crest or other embryonic migratory cells (see the introduction). However, we did notice two features of interest. First, the basement membrane external to the EGL appeared to stain for fibronection (Fig. 1, $B$ and $C$ ), raising the possibility that the cells might be migrating on the basement membrane. Second, there was a cell-free area ahead of the migrating EGL cells (Fig. 1C), and these cells appeared to be migrating into this area.

\section{Relationship of migrating EGL to basement membrane and other structures}

In order to further investigate the relationship of the EGL cells with the basement membrane and the nature of the cell-free zone ahead of the EGL, we prepared samples embedded in Epon and sectioned them either for light microscopy (Fig. 2) or for electron microscopy (Fig. 3). These sagittal sections revealed the following features: First, the cells at the leading edge of the EGL were not in contact with the basement membrane. This is especially clear in Figures $2 A$ and $3, B$ and $C$, but it is also seen in the other figures. Thesc lcading cells are separated from the basement membrane by a layer of glial end feet (Figs. $2 A$ and 

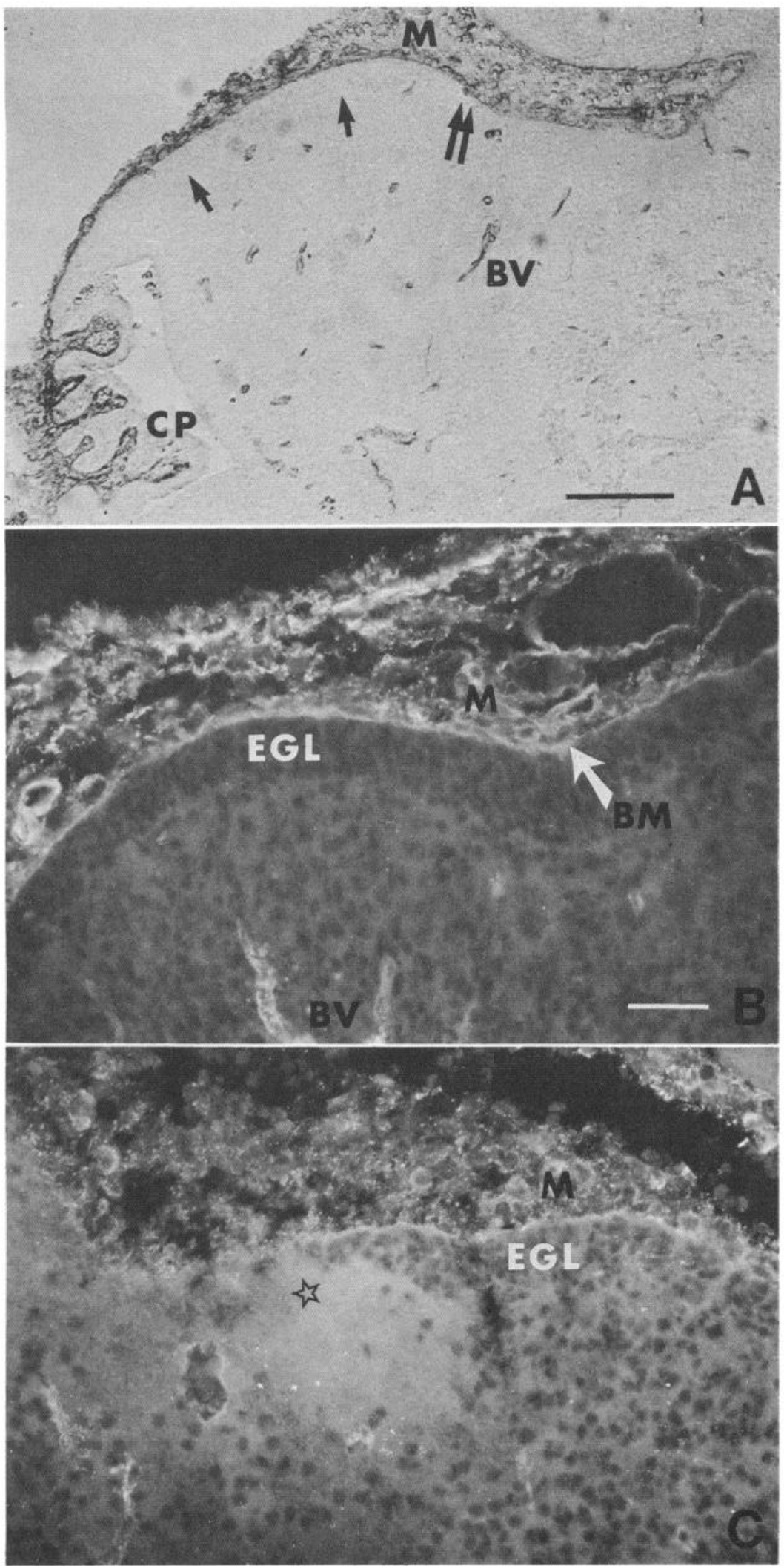

Figure 1. Immunolocalization of fibronectin in embryonic cerebellum. Frozen sagittal sections $(20 \mu \mathrm{m})$ of embryonic rat cerebellum stained with antifibronectin. A, E17 cerebellum stained by the PAP reaction. Note the presence of strong staining for fibronectin in the meningeal layer $(M)$, in the choroid plexus $(C P)$, and associated with blood vessels $(B V)$. The edge of the migrating external granular layer (EGL) is marked by arrows and the leading edge by a double arrow. Note that this layer is free of fibronectin. Bar, $250 \mu \mathrm{m}$. B, E22 cerebellum stained by indirect immunofluorescence. Again note strong staining for fibronectin in the meningeal layer $(M)$ and associated with blood vessels $(B V)$, and the absence of staining from external granular layer $(E G L)$. Also note linear staining for fibronectin at level of basement membrane $(B M)$. Bar, 25 $\mu \mathrm{m}$. $C$, E18 cerebellum stained by indirect immunofluorescence. Note linear staining for fibronectin associated with the basement membrane, the absence of staining of external granular layer $(E G L)$, and cell-free area ahead of EGL (star).
$3 B$ ) and/or by axonal processes (Fig. $3 C$ ). Second, EGL cells positioned back from the apparent leading edge were frequently in contact with the basement membrane, where the layer of glial end feet was interrupted (Fig. $3 A$ ). Well back from the leading edge, glial end feet are rare and most of the basement membrane is covered by EGL cells (not shown). Therefore, the relationship of the EGL cells with the basement membrane is complex.

The EGL cells that had elongated shapes most suggestive of cell migration were those at the apparent leading edge of the EGL and those ahead of, or deep to, the bulk of the EGL (Fig. 
Figure 2. Light micrographs of migrating EGL of E17 rats. Thin (0.5-1.0 $\mu \mathrm{m})$ plastic sections were stained with toluidine blue; the external granular layer (EGL) cells stain strongly. In these sections, which are from the lateral reapproximately sagittally, the EGL cells can be seen to be elongated in the direction of movement of the EGL. The exact appearance of the EGL varies depending on the precise location and orientation of the sections. $A$, The edge of the EGL is well away from the basement membrane $(B M)$, being separated from it by a tongue of glial end feet $(G)$. Ahead of the EGL is a cell-free region occupied by fibers $(F)$, and the EGL cells are oriented parallel to these fibers. Bar, $50 \mu \mathrm{m}$. $B$ and $C$, These sections show a much less prominent layer of glial end feet, although it can be seen that leading cells of the EGL are not directly against the basement membrane $(B M)$. Again, the fibrous area $(F)$ ahead of the EGL is readily seen, and the elongation of EGL cells along the fibers is shown particularly well in panel C. Bar, $25 \mu \mathrm{m}$. gions of the cerebellum and are oriented

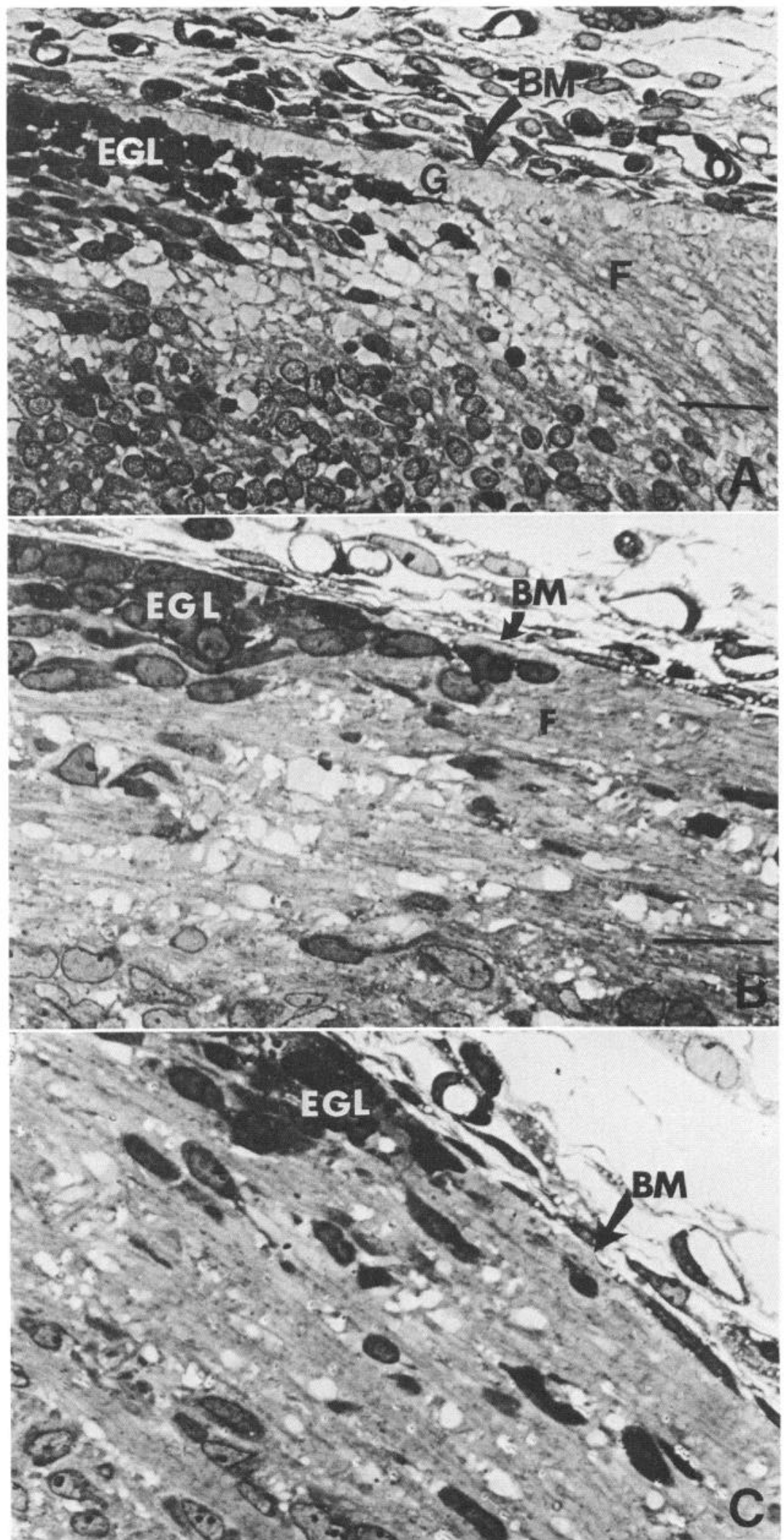

2, $B$ and $C$ ). In contrast, the EGL cells back from the leading edge, which were in contact with the basement membrane, were much more isodiametric and did not give the impression of migration (Fig. $2 B$ ). We did not see elongated cells in contact with the basement membrane.

Further investigation showed that the elongated and appar- ently migrating EGL cells were typically in contact with cell processes (Figs. 2, $A-C$, and 3, $B-D$ ). Although a few of the processes contained rather empty cytoplasm suggestive of glial cells (Fig. $3 B$ ), most of them appeared to be axons because of their content of many longitudinal microtubules (Fig. 3, $C$ and $D)$. The cells were elongated parallel to the processes and in- 

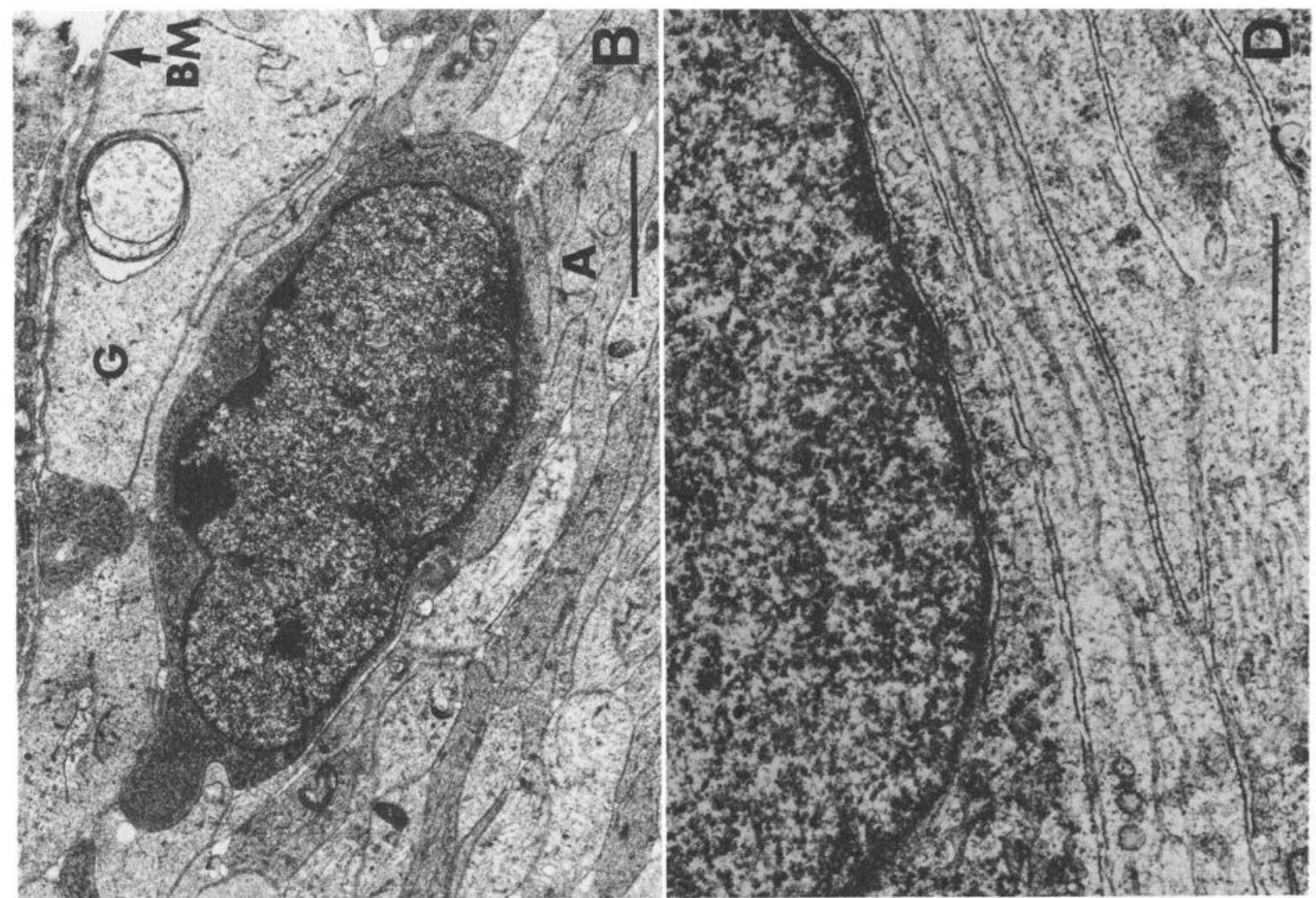

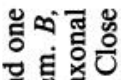

몽

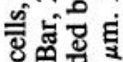

गुंढ휴

용

政

它政

․ㅠำ

일.

a 3 过

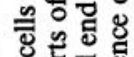

吅, 焉

당

है

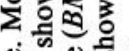

窥这

एक

S

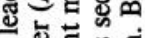

㱐递

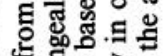

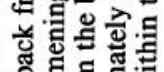
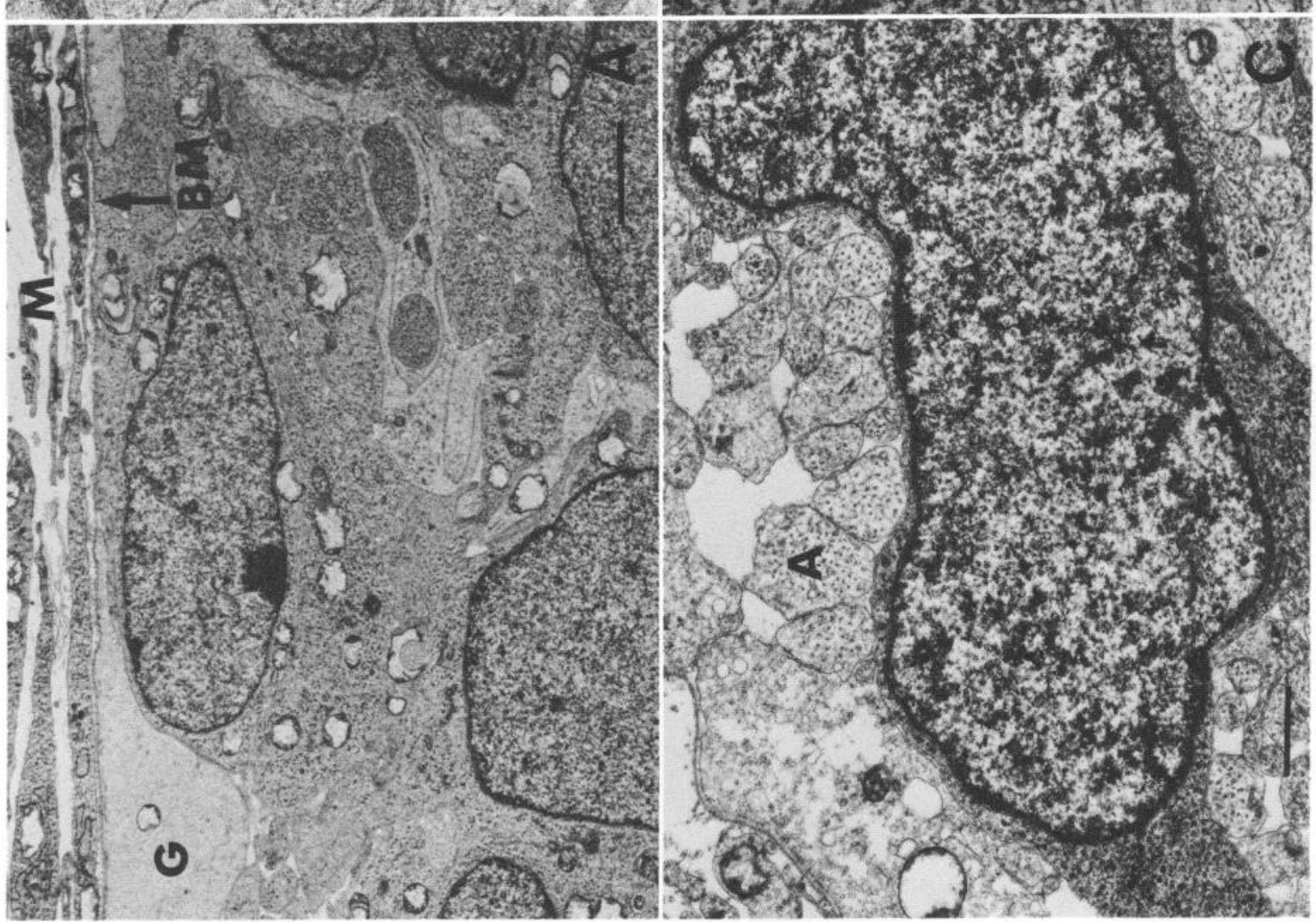

호온

政

초ㅇㅝㅛ

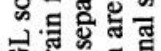

돔의을

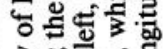

골 모우의

$>$ च

$\$$.

용

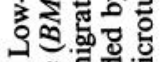

स 름

싱응요

绐

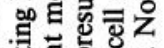

光

总总记造

요으.

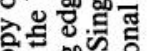

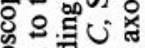

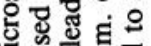

ํㅜㅇㅝ

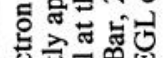

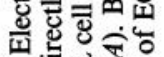

च

nं 5 피

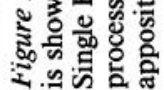




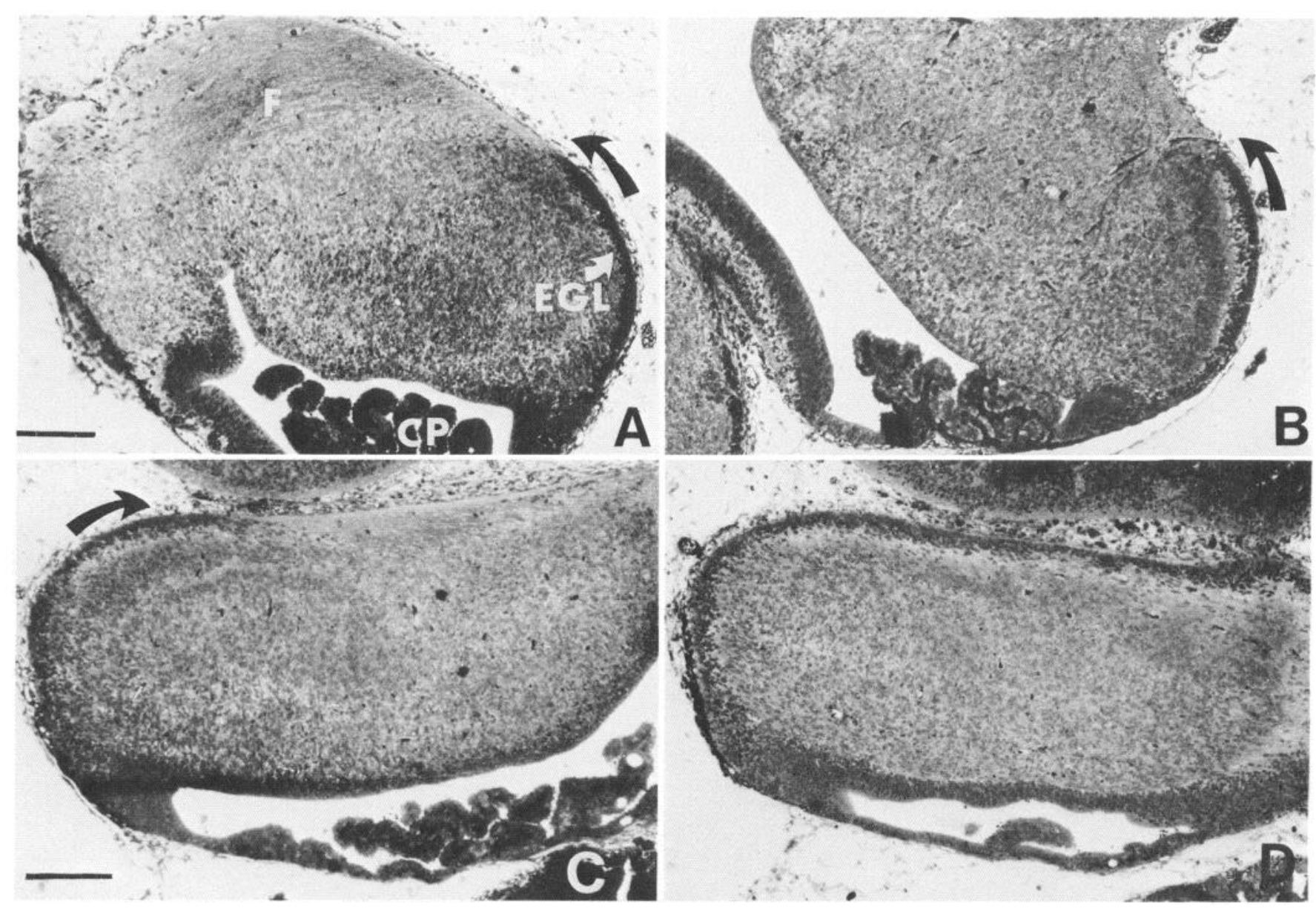

Figure 4. EGL in E17 rat cerebellum. Low-power light micrographs of plastic sections stained with toluidine blue. A, Parasagittal section near lateral edge of cerebellum showing external granule layer $(E G L)$, which appears to be migrating in a caudal to rostral direction (arrow) from a location near the choroid plexus $(C P)$. Ahead of the EGL is a tract of fibers $(F)$ coursing into the cerebellar anlage from the brain stem. $B-D$, Coronal sections, $B$ being the most rostral and $D$ being the most caudal. In $B$ and $C$, the EGL is seen to give the appearance of migrating in a lateromedial direction at the dorsal border of the cerebellum (arrow). Thus, panel $B$ appears very similar to panel $A$, even though the planes of section are approximately perpendicular. In $C$ and $D$, the EGL can be seen at both the dorsal and ventral borders of the cerebellum. Lateromedially oriented cells are seen at lateral, medial, and rostral positions, but not at the ventral edge, where there is a sharp boundary between the EGL and the underlying tissue (see especially panel $D$; also see text for discussion). Bars, $200 \mu \mathrm{m}$.

dividual cells were in close contact with many axons over extended regions (e.g., see Fig. 3, $C$ and $D$ ). This arrangement gave the strong impression that the EGL cells were migrating on the processes, particularly along the axons. There was little, if any, indication that migration was taking place on the basement membrane.

\section{Pattern of axonal processes in the embryonic cerebellum}

The surprising observation discussed above-that EGL cells appear to be migrating along axonal processes-led us to investigate the distribution of the fibers in more detail. The sagittal and parasagittal sections in which we first detected the fiber bundles show a tract of fibers arcing into the cerebellum from a rostral direction; but we noted that the precise pattern observed was very sensitive both to the position of the sections on the mediolateral axis and to the exact orientation (sagittal or slightly off-sagittal). We therefore carried out serial section analyses in all three planes (sagittal, coronal, and horizontal) of the developing cerebellum, concentrating on day E17, when the EGL is in the process of migration. We analyzed both 10-20 $\mu \mathrm{m}$ frozen sections and 1-4 $\mu \mathrm{m}$ plastic sections.

Figures 4 and 5 show some characteristic appearances of the EGL. The pattern of caudorostral migration on a fiber tract (Fig. 2 ) is observed only in sagittal sections in the lateral part of the cerebellum. Midsagittal sections do not show elongated EGL cells or longitudinal sections of a fiber tract, although a cell-free zone is seen ahead of the EGL (Fig. 1C) and axonal processes are observed in cross section (Fig. $3 C$ ). In parasagittal sections of the lateral lobes of the cerebellum, an arc of fibers can be seen coursing to (or from) the leading edge of the EGL from (or to) the brain stem (Fig. $4 A$ ). Analysis of coronal sections revealed the reason for this difference between lateral and medial sagittal sections. Figure $4, B-D$, shows a rostral to caudal series of coronal sections through the cerebellum. Here one observes that the EGL appears to be migrating in a predominantly lateromedial direction over the dorsal surface of the cerebellum. At the ventral margin (e.g., Fig. 4D), the EGL cells do not appear elongated in coronal sections.

Investigation at higher magnification (Fig. $5 B$ ) showed that EGL cells at the dorsal edge of the cerebellum have an appearance very similar to that of lateral parasagittal sections (Fig. 2). That is, EGL cells are elongated along a fiber tract and appear to be migrating along the fibers. The orientation is lateromedial, i.e., perpendicular to that shown in Figure 2. This explains why midsagittal sections do not show elongated EGL cells or longitudinal sections of axons. The fiber tract crosses the midline (Fig. 5A) and is predominantly perpendicular to the sagittal plane. From these results, it appears that a major component 


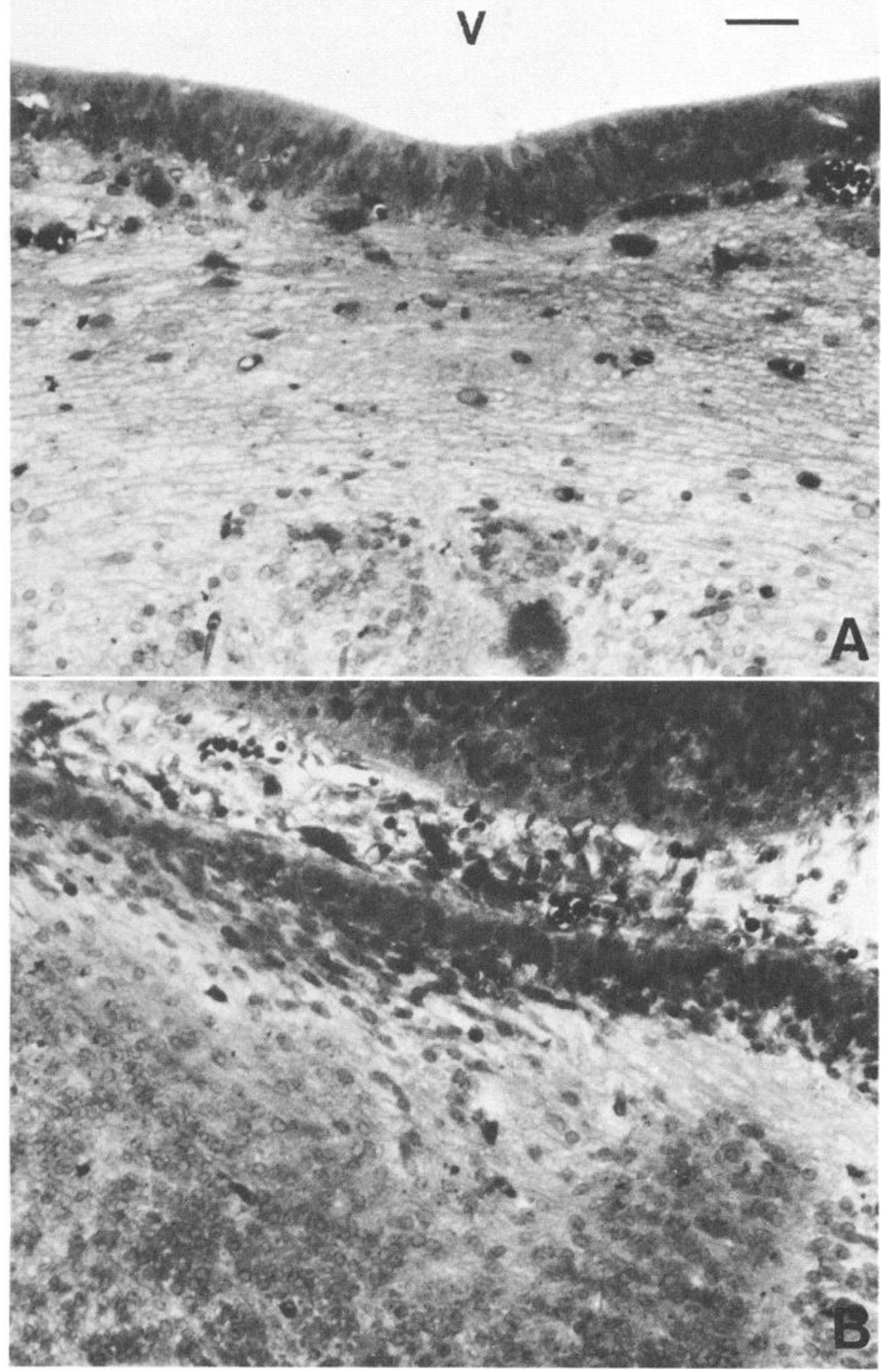

Figure 5. Coronal sections of E17 rat cerebellum. Higher-power views of coronal sections oriented as in Figure 4 $B-D$. Panel $A$ is from the midline of a section somewhat rostral to the one shown in Figure $4 C$, and shows a fiber tract crossing the midline at the level where cerebellum and colliculus are joined. The ventricle $(V)$ of the colliculus is shown above. Panel $B$ is from a section somewhat caudal to that in Figure $3 C$ and shows the EGL and cells detached from it and apparently migrating in a generally lateromedial direction on fibers underlying the EGL. Bar, $50 \mu \mathrm{m}$.

of the EGL migration occurs in a lateromedial direction. At the midline of caudal coronal sections (e.g., Fig. $4 D$ ), some migration also appears to be from the midline groove in a mediolateral or rostral direction.

Therefore, wherever we observe EGL cells that are elongated and give the appearance of migration, they are aligned along axons (Figs. 2-5). However, the fiber tracts associated with these migrating EGL cells are arrayed in a fairly complex pattern, which will be discussed further below.

\section{Discussion}

The major conclusion we wish to draw is that the neuroblasts comprising the migrating EGL of the embryonic cerebellum migrate along preexisting arrays of axons. This conclusion is based on the appearance of the cells, which is typical of migrating cells; that is, the cells are elongated, with both leading and trailing processes, and are aligned with the axons over extended areas of contact (Figs. 2-5). Our data do not support alternative modes of guidance of EGL migration. The cells were not surrounded by a fibronectin-rich matrix, as are many other migrating embryonic cells (see the introduction for references), and they do not even appear to be migrating in contact with the basement membrane surrounding the cerebellar anlage (Figs. 2 and 3).

We are not able to explain adequately the discrepancy between our results and the report of Hatten et al. (1982), suggesting the 


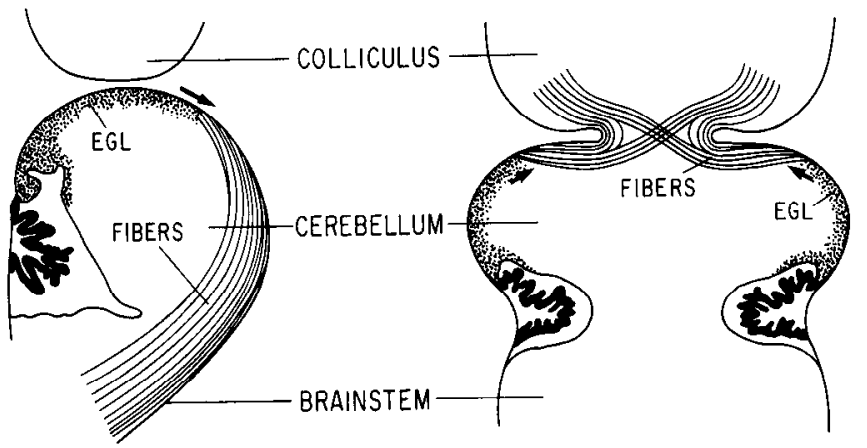

A. Sagittal-lateral

B. Coronal-rostral
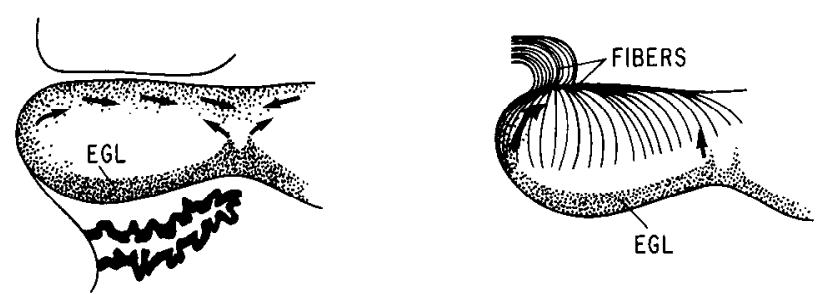

EGL

C. Coronal-caudal

D. 30 Reconstruction

Figure 6. Schematic of disposition of fibers in cerebellum and of migration of EGL. Diagrams of three sections roughly equivalent to Figure 4, $A-D$ (panels $A-C$ ). Panel $D$ presents a very schematic three-dimensional interpretation of the arrangement of the fiber tracts and their involvement in EGL migration. The tracts enter the cerebellum at the rostrolateral junctions with the brain stem $(A)$ and turn caudally $(A)$ and medially over the surface of the cerebellum $(B, C)$. Therefore, the fibers form a layer over the dorsal surface of the cerebellum $(D)$. Some fibers probably enter the colliculus where it connects with the cerebellum in the midline $(B)$. In each half of the cerebellum, the dorsally placed, lateromedially directed fiber tract acts as a substratum for migration (arrows) of EGL cells from the lateral regions medially and perhaps from the medial regions laterally $(C, D)$. The details of this diagram are necessarily speculative.

presence of fibronectin within the EGL during the equivalent cell migration phase in mouse embryos. We can only comment that the staining they reported did not appear typical of extracellular matrix staining seen in other cell migration systems and must have been of low intensity, since an intensifier was necessary to detect it. We have not seen significant staining for fibronectin using several well-characterized antisera, although we have investigated embryonic stages in the rat (E16-E22) exactly equivalent to those studied by Hatten et al. (1982) in the mouse (E13-P0). Schachner et al. (1984) have also failed to detect significant staining for fibronectin in embryonic mouse cerebellum. Indeed, the background fluorescence we observe in the EGL is lower than that in the rest of the cerebellum (Fig. 1, $B$ and $C$ ). We do not rule out the presence of low levels of fibroncctin, but thcre is certainly not very much. It seems clear that this migration is not occurring in a fibronectin-rich extracellular matrix analogous with that of other well-established matrix-guided migrations, such as the neural crest or gastrulation.

We have therefore sought other possible explanations for this migration. Our results suggest that the migration takes place in contact with cell processes - in particular, axons. Their identification as axons rests on their microscopic appearance, in particular, the presence of significant numbers of microtubules (Fig. 3). We have also stained frozen sections with two monoclonal antibodies that recognize neurofilaments, RT97 (Wood and Anderton, 1981) and C2 (M. Yamamoto and H. Tanaka, unpublished observations) and have detected staining of the fiber tracts (unpublished observations). There are also glial cell processes in the area of migration, especially glial end feet apposed to the basement membrane (Figs. 2 and 3), but also some elongated processes running among the axons (not shown). We have further detected faint staining for glial fibrillar acidic protein (unpublished observations); little staining is to be expected in embryonic rodent tissue (Bignami and Dahl, 1973). Since glial cells are present, their processes could contribute to the guidance of EGL migration, but it is our belief that the axons are probably more important, since they are present in large numbers and extended contacts between them and the EGL cells are easily detected (e.g., see Fig. 4). Serial electron-microscopic reconstruction will be necessary to resolve this point definitively. It is also naturally impossible to prove that the axons guide the migration on the basis of microscopy alone. We have not observed any specialized junctions in our electron-microscopic studies, so the nature of the suggested interaction is unclear. It can be viewed under the general rubric of "contact guidance" without presuming or excluding specific molecular interactions. These could include cell-cell interactions or other extracellular matrix molecules, such as laminin. Ideally, one would like to ablate the axons and test for inhibition of migration, but this has not yet been possible.

Two further questions are raised by these results. First, what is the source of the axons associated with the migration of the EGL? Second, could guidance of cell migration by axons be of significance elsewhere during brain development? We do not have satisfactory answers to either of these questions, but we can offer some discussion.

The fiber bundles in question are present before the onset of external granule cell migration. They are certainly present on E15 and probably earlier (unpublished observations). There are several earlier reports of fiber tracts present in the developing cerebellum (Altman, 1982; Altman and Bayer, 1978a; Tello, 1940; West and Del Cerro, 1976), bul we are unaware of any definitive determination of their sources. Altman and Bayer $(1978 \mathrm{a}, \mathrm{b})$ have noted the presence of an "unidentified fiber tract" beneath the expanding EGL, and have suggested that they could form a substrate for migration. There is a possibility that the tract could contain efferent fibers from the developing Purkinje cells or deep nuclear neurons, but this seems rather unlikely since the birthdates of these cells range from E13 to E16, and they have not undergone much differentiation by the stage under consideration here (Altman, 1982; Altman and Bayer, 1978a). West and Del Cerro (1976) have suggested that parallel fibers of granule cells could arise very early; this is a possibility. However, it appears more likely that these are afferent fibers entering the cerebellar anlage from elsewhere-but from where?

The cerebellum is connected to other parts of the brain at threc placcs. At cach rostrolatcral margin, the ccrcbcllum is continuous with the brain stem (Fig. $4 A$ ) and, in the midline, there is a connection between the cerebellum and the colliculus (Fig. $5 A$ ). Fiber bundles can be seen entering (or leaving) the developing cerebellum at each of these points. Our interpretation of the disposition of the fiber tracts entering the cerebellum and their role in guidance of EGL migration is shown in Figure 6. Two bundles of fibers enter the cerebellum from the brain stem via each lateral margin (see Fig. $4 A$ ) and fan out over the whole dorsal surface of the cerebellum, where they form a substratum for migration of the developing EGL. In the lateral regions of the cerebellum, some of these entering fibers may pass in a rostrocaudal direction; but the majority run generally toward the midline, and these lateromedially directed fiber tracts are readily seen in the coronal sections (Figs. 4, 5). The tracts appear to cross in the midline (see also Altman and Bayer, 1978a), and some fibers appear to pass up into the colliculus, although whether they do so ipsilaterally or contralaterally is unclear. Some fibers appear to diverge from these lateromedial tracts and pass in a generally caudal direction near the dorsal 
surface of the cerebellum, which again serves as a substratum for migration of the EGL. Altman and Bayer (1985) have very recently described the pattern of expansion of the EGL, and their description conforms well with that offered here.

If this interpretation (Fig. 6) is generally correct, then the major source of these fiber tracts is the brain stem. We have investigated two possible sources - the locus coeruleus and the raphe nuclei-using antibodies to tyrosine hydroxylase and dopamine hydroxylase and to serotonin. None of these antibodies stained the fiber tracts in question (unpublished observations). Therefore, these axons do not appear to be catecholaminergic or serotonergic. They seem most likely to originate from the vestibular or trigeminal projections (primary or secondary) or from the spinocerebellar tracts. Another possibility is that the fibers could arise from the neurons of the olivary nuclei. It has been suggested that these neurons, which have been born and are migrating ventrally by this stage, could spin out their axons during the migration (Altman, 1982; Altman and Bayer, 1978b; Goffinet; 1983), but since this projection is contralateral (e.g., Sotelo et al., 1984), these axons would have to travel a long distance to reach the cerebellum by E17-E18. Tello (1940) describes fibers entering the cerebellar anlage of the mouse prior to EGL migration, and he suggests that the first fibers to enter are vestibular projections, and that these are followed by others (bulbocerebellar, olivocerebellar) prior to the migration phase. The fibers could also be a transient population. Our current data do not allow us to distinguish clearly among these various possibilities, and we are in the process of conducting further studies to determine the source(s) of these fibers. This question is of some interest because of the intriguing possibility of an early relationship between the cerebellar afferents that later give rise to mossy or climbing fibers and the precursors of granule cells with which they could connect. If such a relationship were established early, it could have significant implications for the later architecture and connectivity of the cerebellum.

Finally, there is the question of whether a relationship between cell migration and preexisting fiber tracts is unique to the developing cerebellum or could be a more general mechanism for guidance during development of the brain. The recent report of Moody and Heaton (1983c) describing the morphology of chick trigeminal motor neurons during their tangential migration from the midline of the metencephalon to the lateral nucleus shows images of cells migrating on axons very similar to those we describe here. These authors intcrpreted their illustrations as showing migration of these motor neurons on the axons of adjacent migrating cells. However, it seems likely to us that these fiber tracts could include afferent axons from the trigeminal ganglion, especially since ablation of the ganglion (Moody and Hcaton, 1983a) or retardation of the entry of the ganglion cell axons (Moody and Heaton, 1983b) both prevent migration of the trigeminal motor neurons until axons do enter the brain stem, at which point motor neuron migration commences. Therefore, this system also may demonstrate migration of neuroblasts on the axons of other cells.

Two obvious situations that may offer other examples are the migration of the cells of the olivary and pontine nuclei. These cells originate in a zone in the floor of the fourth ventricle, very close to the site of origin of the EGL (Altman and Bayer, 1978b; Goffinet, 1983; Taber-Pierce, 1966). They then migrate close to the lateral surface of the medulla to their final positions near the ventral midline of the medulla. These migrations occur at around the same time as the migration of the cerebellar EGL, and there appear to be fiber tracts in the appropriate general locations (Altman and Bayer, 1978b; and our unpublished observations). It will be of some interest to see whether a similar correlation between preexisting axons and migrating neuroblasts can be detected for these two groups of neurons. Other cell migrations, such as those suggested as occurring during the post- natal development of the hippocampus (Altman, 1966; Altman and Das, 1966) and during development of the pulvinar nucleus in the fetal human thalamus (Rakic and Sidman, 1969) also appear worthy of study. It is an intriguing hypothesis that guidance of cell migration by axons might be a general mechanism to be added to the much discussed model of guidance by radial glial cells.

\section{References}

Altman, J. (1966) Autoradiographic and histological studies of postnatal neurogenesis. II. J. Comp. Neurol. 128: 431-474.

Altman, J. (1972a) Postnatal development of the cerebellar cortex in the rat. I. The external germinal layer and the transitional molecular layer. J. Comp. Neurol. 145: 353-398.

Altman, J. (1972b) Postnatal development of the cerebellar cortex in the rat. III. Maturation of the components of the granular layer. J. Comp. Neurol. 145: 465-514.

Altman, J. (1982) Morphological development of the rat cerebellum and some of its mechanisms. Exp. Brain Res. (Suppl.) 6: 8-46.

Altman, J., and S. A. Bayer (1978a) Prenatal development of the cerebellar system in the rat. II. Cytogenesis and histogenesis of the deep nuclei and the cortex of the cerebellum. J. Comp. Neurol. 179: 23-48.

Altman, J., and S. A. Bayer (1978b) Prenatal development of the cerebellar system in the rat. II. Cytogenesis and histogenesis of the inferior olive, pontine gray, and the precerebellar reticular nuclei. J. Comp. Neurol. 179: 49-76.

Altman, J., and S. A. Bayer (1985) Embryonic development of the rat cerebellum. I. Delineation of the cerebellar primordium and early cell movements. J. Comp. Neurol. 231: 1-26.

Altman, J., and O. D. Das (1966) Autoradiographic and histological studies of postnatal neurogenesis. Int. J. Comp. Neurol. 126: 337390.

Atherton, B. T., and R. O. Hynes (1981) A difference between plasma and cellular fibronectins located with monoclonal antibodies. Cell 25: 133-141.

Bignami, A., and D. Dahl (1973) Differences of astrocytes in the cerebellar cortex and the pyramidal tracts of the newborn rat. An immunofluorescence study with antibodies to a protein specific to astrocytes. Brain Res. 49: 393-402.

Boucaut, J. C., T. Darribere, H. Boulekbache, and J. P. Thiery (1984) Prevention of gastrulation but not neurulation by antibodies to fibronectin in amphibian embryos. Nature 307: 364-367.

Choi, M. G., and R. O. Hynes (1979) Biosynthesis and processing of fibronectin in NIL8 hamster cells. J. Biol. Chem. 254: 12050-1 2055.

Duband, J. L., and J. P. Thiery (1982) Distribution of fibronectin in the early phase of avian cephalic neural crest cell migration. Dev. Biol. 93: 308-323.

Goffinet, A. M. (1983) The embryonic development of the inferior olivary complex in normal and reeler $\left(\mathrm{rl}^{\text {orl }}\right)$ mutant mice. J. Comp. Neurol. 219: 10-24.

Hatten, M. E., M. B. Furie, and D. B. Rifkin (1982) Binding of developing mouse cerebellar cells to fibronectin: A possible mechanism for the formation of the external granular layer. J. Neurosci. 2: 11951206.

Hynes, R. O. (1981) Fibronectin and its relation to cellular structure and behavior. In Cell Biology of Extracellular Matrix, E. D. Hay, ed., pp. 295-334, Plenum, New York.

Hynes, R. O., and A. T. Destree (1978) Relationships between fibronectin (LETS protein) and actin. Cell 25: 875-886.

Hynes, R. O., and K. M. Yamada (1982) Fibronectins: Multifunctional modular glycoproteins. J. Cell Biol. 95: 369-377.

Jones, T. R., E. Ruoslahti, S. C. Schold, and D. D. Bigner (1982) Fibronectin and glial fibrillary acidic protein expression in normal human brain and anaplastic human gliomas. Cancer Res. 42: 168177.

Korneliussen, H. K. (1968) On the ontogenetic development of the cerebellum (nuclei, fissures and cortex) of the rat, with special reference to regional variations in corticogenesis. J. Hirnforsch. 10:379412.

Lee, G., R. Hynes, and M. Kirschner (1984) Temporal and spatial regulation of fibronectin in early Xenopus development. Cell 36:729740. 
Lofberg, J., K. Ahlfors, and C. Fallstrom (1980) Neural crest cell migration in relation to extracellular matrix organization in the embryonic axolotl trunk. Dev. Biol. 75: 148-167.

Mautner, V., and R. O. Hynes (1977) Surface distribution of LETS protein in relation to the cytoskeleton of normal and transformed cells. J. Cell Biol. 75: 743-758.

Mayer, B. W., Jr., E. D. Hay, and R. O. Hynes (1981) Immunocytochemical localization of fibronectin in embryonic chick trunk and area vasculosa. Dev. Biol. 82: 267-286.

Miale, I., and R. L. Sidman (1961) An autoradiographic analysis of histogenesis in the mouse cerebellum. Exp. Neurol. 4: 277-296.

Minier, L. N., R. S. Lasher, and P. F. Erickson (1981) Distribution of the LETS protein (fibronectin) in rat cerebellum. Cell Tissue Res. 214: 491-500.

Moody, S. A., and M. B. Heaton (1983a) Developmental relationships between trigeminal ganglia and trigeminal motoneurons in chick embryos. I. Ganglion development is necessary for motoneuron migration. J. Comp. Neurol. 213: 327-343.

Moody, S. A., and M. B. Heaton (1983b) Developmental relationships between trigeminal ganglia and trigeminal motoneurons in chick embryos. II: Ganglion axon ingrowth guides motoneuron migration. J. Comp. Neurol. 213: 344-349.

Moody, S. A., and M. B. Heaton (1983c) Ultrastructural observations of the migration and early development of trigeminal motoneurons in chick embryos. J. Comp. Neurol. 216: 20-35.

Newgreen, D., and J. P. Thiery (1980) Fibronectin in early avian embryos: Synthesis and distribution along the migration pathways of neural crest cells. Cell Tissue Res. 211: 269-291.

Newgreen, D. F., I. L. Gibbins, J. Sauter, B. Wallenfels, and R. Wutz (1982) Ultrastructural and tissue-culture studies on the role of fibronectin, collagen and glycosaminoglycans in the migration of neural crest cells in the fowl embryo. Cell Tissue Res. 221: 521-549.

Paetau, A., K. Mellstrom, A. Vaheri, and M. Haltia (1980) Distribution of a major connective tissue protein, fibronectin, in normal and neoplastic human nervous tissue. Acta Neuropathol. (Berl.) 51: 47-51.

Rakic, P. (1971) Neuron-glia relationship during granule cell migration in developing cerebellar cortex. A Golgi and electronmicroscopic study in Macacus rhesus. J. Comp. Neurol. 141: 283-312.

Rakic, P. (1972) Mode of cell migration to the superficial layers of fetal monkey neocortex. J. Comp. Neurol. 145: 61-84.

Rakic, P. (1973) Kinetics of proliferation and latency between final division and onset of differentiation of the cerebellar stellate and basket neurons. J. Comp. Neurol. 147: 523-546.
Rakic, P. (1981) Neuronal-glial interaction during brain development. Trends Neurnsci. 4: 184-187.

Rakic, P., and R. L. Sidman (1969) Telencephalic origin of pulvinar neurons in the fetal human brain. Z. Anat. Entwickl. Gesch. 126: 5382.

Rovasio, R. A., A. Delouvee, K. M. Yamada, R. Timpl, and J. P. Thiery (1983) Neural crest cell migration: Requirements for exogenous fibronectin and high cell density. J. Cell Biol. 96: 462-473.

Schachner, M., G. Schoonmaker, and R. O. Hynes (1978) Cellular and subcellular localization of LETS protein in the nervous system. Brain Res. 158: 149-158.

Schachner, M., A. Faissner, J. Kruse, J. Lindner, D. H. Meier, F. G. Rathjen, and H. Wernecke (1983) Cell type specificity and developmental expression of neural cell-surface components involved in cell interactions and of structurally related molecules. Cold Spring Harbor Symp. Quant. Biol. 48: 557-568.

Senger, D. R., and R. O. Hynes (1978) C3 component of complement secreted by established cell lines. Cell 15: 375-384.

Sidman, R. L., and P. Rakic (1973) Neuronal migration with spccial reference to developing human brain: A review. Brain Res. 62: 1-35.

Sotelo, C., F. Bourrat, and A. Triller (1984) Postnatal development of the inferior olivary complex in the rat. II. Topographic organization of the immature olivocerebellar projection. J. Comp. Neurol. 222; 177-199.

Taber-Pierce, E. (1966) Histogenesis of the nuclei griseum pontis, corpus pontobulbaris and reticularis tegmenti pontis (Bechterau) in the mouse. An autoradiographic study. J. Comp. Neurol. 126: 219 240.

Tello, J. F. (1940) Histogenese du cervelet et ses voies chez la souris blanche. Trav. Iab. Rech. Biol. Univ. Madrid 32: 1-74.

Thiery, J. P., J. L. Duband, and A. Delouvee (1982) Pathways and mechanisms of avian trunk neural crest cell migration and localization. Dev. Biol. 93: 324-343.

Tosney, K. W. (1978) The early migration of neural crest cells in the trunk region of the avian embryo: An electron microscopic study. Dev. Biol. 62: 317-333.

Tosney, K. W. (1982) The segregation and early migration of cranial neural crest cells in the avian embryo. Dev. Biol. 89: 13-24.

West, M. J., and M. Del Cerro (1976) Early formation of synapses in the molecular layer of the fetal rat cerebellum. J. Comp. Neurol. 165: $137-160$

Wood, J. N., and B. H. Anderton (1981) Monoclonal antibodies to mammalian neurofilaments. Biosci. Rep. 1: 263-268. 